\title{
PSA Level Greater than or Equal to Twenty-Five
}

National Cancer Institute

\section{Source}

National Cancer Institute. PSA Level Greater than or Equal to Twenty-Five. NCI

Thesaurus. Code C137708.

A blood concentration of prostate specific antigen greater than or equal to $25 \mathrm{ng} / \mathrm{mL}$. 